\title{
IDÉIAS
}

\section{Breve avaliação das reformas administrativas no Brasil}

\author{
Gileno Fernandes Marcelino (")
}

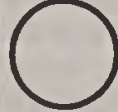

entendimento da reforma administrativa não é o de um processo isolado, mas de um fato relacionado com os objetivos da sociedade, no sentido de promover o desenvolvimento econômico e social. Nesse sentido, a reforma/modernização administrativa pode ser considerada um conceito típico de países em processo de desenvolvimento, à medida que, neste tipo de sociedade, ocorre uma profunda defasagem entre os objetivos do Governo de desenvolvimento e o instrumental administrativo necessário à sua consecuçăo.

A preocupaça com a reforma administrativa relaciona-se com a procura de maior eficácia e eficiência da organização pública. Esta c., tipicamente, a situação atual, quando se torna urgente e inadiável uma reforma do aparato administrativo governamental para viabilizar o recém-implantado Programa de Estabilização Econòmica c o PND Plano Nacional de Desenvolvimento da Nova Republica.

\section{AS REFORMAS}

No Brasil, teve inicio, na decada de 30 , o ciclo das reformas administrativas planejadas. $\wedge$ caracteristica mais marcante do periodo inicial que se estendeu até meados da década de $\mathbf{4 0}$ foi a ênfase na reforma dos meios (atividades de administração geral) mais do que na dos próprios fins (atividades substantivas).

De acordo com Wahrlich (1), a reforma nesse periodo tinha caráter globalista e suas principais áreas de ação foram:

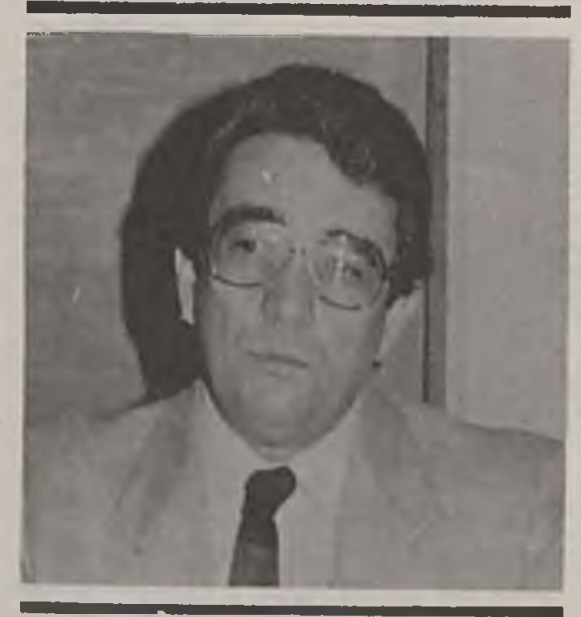

- a administração do pessoal, tendo o sistema de mérito como pedra angular da reforma;

- a administração do material, em especial, sua simplificaçao e padronizaçăo;

- o orçamento e administração orçamentária, com a introdução da concepção de orçamento como um plano de administração;

- a revisão de estruturas e racionalização de métodos.

Outra importante caracteristica desse periodo foi a orientação nitidamente autocrática, impositiva, da reforma, o que, aliado à sua quaseexclusiva preocupação com a administração-meio, contribuiu decisivamente para que a administraçao assumisse a função de um sistema fechado.

Esse ciclo reformista entrou em colapso em 1945 e somente sete anos mais tarde - em 1952 - esboçou-se um novo ciclo que se estendeu durante dez anos, durante os quais se realizaram estudos, elaborararam-se

- Secretário-Geral do Ministério Extraordinário de Administraçăo e Professor da Faculdade de Economia e Administração da Universidade de Sáo Paulo - FEA/USP.

projetos, que não chegaram, entretanto, a concretizar-se. É também a partir da segunda metade da década de 50 que começa a configurar-se um projeto nacional de desenvolvimento.

Embora tenham ocorridoanteriormente outras tentativas de melhoria da ação pública, é a partir desta década que surge uma constatação da profunda ineficiência do instrumental administrativo que passa a ser exigido por uma atuação mais ampla e intensa dos poderes públicos. Surgem, então, os programas oficiais de reforma administrativa objetivando a reorganização geral dos serviços públicos, dentro de esquemas de ação concentrada e propondo metas ambiciosas em termos de prazos e resultados.

Com exceção da reforma do $\mathrm{Mi}$ nistério da Fazenda e do Sistema Tributário Nacional (2), planejada e implantada de 1962 a 1966, somente em 1967 retomou-se efetivamente o caminho da reforma, desta vez com caráter de permanência, com a institucionalização de um órgão próprio para a condução do processo - o ERA (3) - Escritório de Reforma Administrativa, substituido posteriormente pela SEMOR (4) - Secretaria de Modernização Administrativa, passando a reforma administrativa a integrar o próprio Plano Nacional de Desenvolvimento.

Nesse contexto, a edição do Decreto-lei 200 em 1967 (5) representou, sem dúvida, um terceiro momento importante dentro das tantativas dereforma administrativa promovidas pela administraçăo pública brasileira, ao estabelecer uma nova abertura conceitual, permitindo acelerar um processo de 


\section{IDÉIAS}

adaptação da máquina administrativa no sentido de sua eficácia maior.

Note-se bem que o entendimento não é de que o Decreto-lei 200 propiciou o desenvolvimento de um programa oficial de reforma administrativa bem-sucedido e, sim, de que aquela norma legal facilitou o processo de mudança em andamento, à medida que configurou alguns preceitos adequados à evolução da administração pública brasileira.

Ao contrário das tentativas anteriores de reforma administrativa, marcadas por um sentido de condução do processo e pelas tentativas de soluçōes globais, o Decreto-lei 200 constituiu-se mais em um plano indicativo ou carta de intenções estabelecendo conceitos e princípios do que em uma norma deterministica.

Entre os conceitos e principios que facilitaram o processo de reforma administrativa, podem ser citados:

- adota o principio de descentralização institucional, inclusive incorporando novas modalidades de instrumentos, como é o caso de empresa pública;

- recomenda, no contexto da descentralização, a transferência de atividades também para o setor empresarial privado;

- dá maior flexibilidade ao processo de implantação da reforma, permitindo que a regulamentação de medidas relacionadas com a reorganização seja aprovada a nivel de $\mathrm{Mi}$ nistérios;

- estabelece o conceito de sistemas administrativos para as funçoes comuns a todos os órgãos, o que, em principio, facilita a descentralização da gestāo de recursos (pessoal, material, finanças);

- recomenda, no contexto da descentralização, a transferência de atividades também parà o setor empresarial privado;

- dá maior flexibilidade ao processo de implantação da reforma, permitindo que a regulamentação de medidas relacionadas com a reorganização seja aprovada a nivel de $\mathrm{Mi}$ nistérios:

- estabelece o conceito de sistemas administrativos para as funçōes comuns a lodos os órgãos, o que, em principio, facilita a descentralizaçào da gestão de recursos (pessoal, material, finanças).

Em seminário realizado na Fun- dap, em março de 1985, sobre o Decreto-lei 200, a maioria dos especialistas ali reunidos concordou que essa norma legal marcou o inicio efetivo do processo de descentralização da Administração Pública no Brasil. De acordo com um dos conferencistas, Aluizio Loureiro Pinto (5), os principios do planejamento, da descentralização e do controle teriam fixado os parâmetros para o processo decisório nacional, a flexibilidade administrativa e a garantia do controle dos atos dos administradores, segundo a regra de que a auloridade vem acompanhada da responsabilidade.

Não obstante, o Decreto-lei 200 não se constituiu em um instrumento capaz de imprimir um ritmo mais

Decreto-lei 200 nāo
se constituiu em
instrumento capaz de
imprimir ritmo mais
intenso ou de maior
eficácia aos
programas de reforma
administrativa
oficiais. Instrumentos
nele criados nāo
resultaram em processo
dirigido de
reorganizaçāo do
setor público.

intenso ou de maior eficácia aos programas de reforma administrativa oficiais. Em outras palavras, os instrumentos definidos por aquela norma não resultaram em nenhuma experiência mais consistente em termos de um processo dirigido de reorganização administrativa. O processo continuou até 1984 tendo caracteristicas de espontaneidade e conseguiu-se muito pouco em termos de melhoria de eficiência da administração, um aspecto que continua sendo um importante objetivo a atingir com a assunção do poder do Governo da Nova República.

Portanto, a avaliação das tentativas realizadas demonstra o quaselotal fracasso das reformas adminisirativas no periodo analisado, pelo menos se entendidas em termos de melhoria de eficáçia e eficiência da ação pública. Houve, isto sim, em todo o periodo uma transformaçãc profunda na administração públič brasileira, inclusive gerando instrumentos de açoes para alguns setores da ação pública, sem que, para este fato, ocorressem maiores contribuições dos órgãos responsáveis pela reform a ad min istrativa. Consideram-se, nesse caso, por exemplo, as medidas adotadas pelo Governo Federal em relação à área econômica e que determinaram a criação da Petrobrás, Eletrobrás e uma série de empresas públicas e sociedades de economia mista.

Verificou-se, pois, neste periodo, um processo de mudança administrativa bastante intensa, mas que ocorreu de forma mais ou menos espontânea, motivada por pressỏes externas e internas, no sentido de uma eficácia maior da ação pública, com reduzida orientação em um contexto mais amplo de desenvolvimento geral da administração pública.

Por outro lado, as reformas administrativas oficiais desde 1930 apresentaram profundas inadequações em face da realidade, hoje em dia já bem diagnosticadas e que poderiam ser resumidas em três aspeclos:

- foram moldadas segundo mode-

\section{REFERENCIAS BIBLIOGRAFICAS}

1. WahRLICH, Beatriz M. de Souza Reforma Administrativa Federal: Passado e Presente. Revisōes de Administraçoes Pública: 8 (2): p. 27-75 abril/jun 1974.

2. BRASIL - Lei $n^{2} 5.172$ - publicado no Diário Oficial da União, em 25 de outubro de 1966 - Departamento de imprensa Nacional, Brasilia

3. BRASIL - Decreto $n^{2} 61.323$ - publicado no Diário Oficial da Uniăo em 19 de setembro de 1967 - Departamento de Imprensa Nacional, Brasilia

4. BRASIL - Decreto $n^{8} 70.793$ - pu blicado no Diário Oficial da União em 5 de julho de 1972 e Portaria $n^{2} 69$ do Ministério do Planejamento de 26 de julho de 1972

5. BRASIL - Decreto-lei $n^{2} 200$, de 25 de fevereiro de 1967. Departamento de Imprensa Nacional, Brasilia 1967

6. LOUREIRO Pinto, Aluizio - 0 Decreto-lei $n^{2} 200$ como estratéaia de modernização institucional: FUNDAPFundação do Desenvolvimento Administrativo. Administraçáo Pública Brasileira - 1984/Sáo Paulo, D. 5-21/Documento de Trabalho, 41 


\section{IDÉIAS}

los ou concepções de racionalidade não ajustáveis à realidade brasileira;

* atuaçáo preterencial sobre os meios, não estando voltadas para o objetivo de instrumentação das políticas do setor público;

* falta de um sentido de estratégia que permitisse a viabilidade de projetos dentro de um esquema de superação de resistências, acomodação de conflitos, adequação aos recursos disponíveis e determinação de finalidades no tempo.

Reforma Administrativa é uma tomada de consciência, por parte de dirigentes e dirigidos, da necessidade de modernizar o quadro governamental.

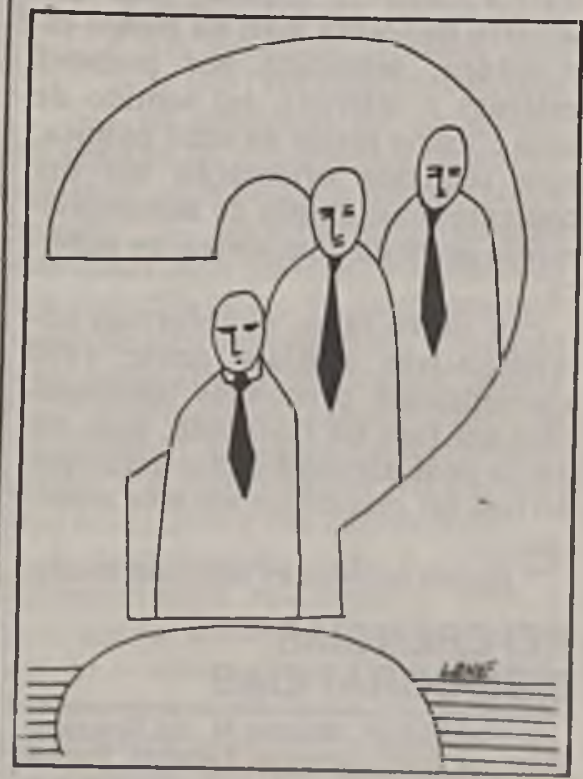

Foi por compreender bem esse problema e atendendo a uma demanda social por maior eficiência e eficácia no Governo que o presidente José Sarney decidiu, em meados do ano passado, iniciar um novo processo de reforma administrativa.

Através dos Decretos $n^{\prime s} 91.300$ de 04 de junho de 1985 e 91.501 de 31 de julho de 1985, determinou ao ministro Aluizio Alves fosse iniciada uma ampla reforma da Administração Pública Federal sob a liderança do Ministério da Administraçào. E o objetivo claramente definido, desde o inicio, nos documentos de diretrizes e nos pronunciamentos do Ministro da Administracão é o de "preparar a Administração para o novo regime democrático e particularmente, para execução do Plano Nacional de Desenvolvimento do governo José Sarney".

\section{Desenvolvimento, capacidade e reforma administrativa}

\author{
Por Gerald E. Caiden "
}

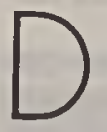

esde o inicio dos anos 50, a modernização administrativa vem sendo cada vez mais reconhecida como parte integrante do processo de desenvolvimento. A capacidade de assumir novas tarefas, lidar com complexidade, compreender o conflito, solucionar novos problemas, mobilizar recursos, aprender com a experiência e a incerteza e lidar com crises e turbulências depende de uma capacidade administrativa significativamente ampliada, baseada em grande parte em maior profissionalização, burocratização, mecanizacão c talento administrativo. Como os sistemas administrativos mudam lentamente e de maneira conservadoramente crescente, a reação e a adaptação naturais são inadequadas para se enfrentarem os desafios do desenvolvimento. É necessário algo mais rípido e mais radical: programas organizados de reforma administrativa nos principais setores de desenvolvimento, particularmente nos canais de menor reação, mais entorpecidos, que tolhem o progresso e os esforços de desenvolvimento em outros pontos.

O freio administrativo ao desenvolvimento é reconhecido universalmente. Durante as últimas duas décadas, vários paises cuja capacidade administrativa deve ser altamente considerada segundo quaisquer critérios instigaram amplas revisões de seu mecanismo de Governo, do desempenho das empresas públicas e do setor privado e anunciaram pla-

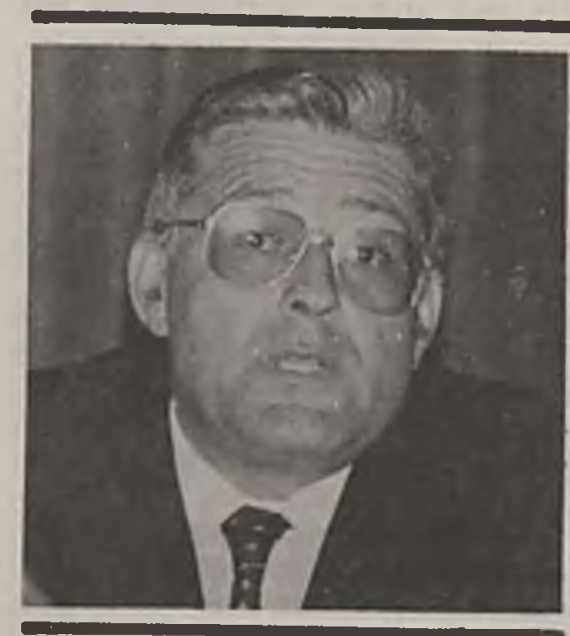

nos para um exame estrutural e rápida expansão do ensino e do treinamento administrativos. Um número impressionante de novos estados obsedados com os problemas de sobrevivência, instabilidade e pobreza da sociedade alterou radicalmente seus sistemas administrativos ou chamou especialistas estrangeiros para dar. orientação a respeito da consecução de substancial melhoria no desempenho administrativo. Órgãos internacionais e multinacionais foram instados a fornecer assistência e ajuda em projetos de reformas setoriais e administrativas e atenderam dentro das limitaçes de seus meios. Tornou-se cada vez mais evidente que os conhecimentos e a experiência pertinentes eram escassos e inadequados. Como resultado, a assistência à ampliação da capacidade administrativa e à melhoria dos pro-

- Prolessor e conferencisla, diretor do Departamento de Ciência Politica da Universidade de Haifa, Estados Unidos, Caiden esleve recentemente no Brasil, onde pronunciou uma série de palestras, inclusive esta na Fundação-Centro de Formaçăo do Servidor Publico, Funcep, em Brasilia, cujo texto se publica a seguir, por seu valor como visáo universal dos esforços de modernizacăo e reforma dos servicos públicos, em vários paises. 